МАТЮКИН Сергей Владимирович - кандидат экономических наук, доцент кафедры менеджмента и экономической безопасности Пензенского государственного университета (440026, Россия, г. Пенза, ул. Красная, 40; msv@тырепzа.ru)

\title{
МОДЕЛИ ТРАНСФОРМАЦИИ ХОЛДИНГОВЫХ СТРУКТУР В КЛАСТЕРЫ: СЦЕНАРИИ В УСЛОВИЯХ РОССИЙСКОЙ ЭКОНОМИКИ
}

\begin{abstract}
Аннотация. Современные экономисты доказали, что производственные холдинги, распространенные во многих отраслях экономики, имеют существенные ограничения при решении задач оптимального использования ресурсов, развития инноваций. Эффективными моделями организации производственных комплексов в развитых странах являются кластеры.

По результатам анализа отечественного и зарубежного опыта автор разрабатывает сценарные модели формирования территориально-производственных кластеров путем их трансформации из существующих холдинговых структур для решения задач перехода экономических систем на инновационные модели организации и развития, формирования новых высокопродуктивных источников роста высокотехнологичной экономики.
\end{abstract}

Ключевые слова: кластерная политика, территориальные кластеры, трансформация холдинга, модель формирования кластера, потенциал кластеризации

$\mathrm{K}$ ластеры являются современными моделями эффективной организации производственных комплексов. Они обеспечивают высокую конкурентоспособность предприятий за счет значительной степени их концентрации и кооперации, формирование инфраструктуры и сервисов общего пользования, развитие малого и среднего предпринимательства путем активного аутсорсинга, реализацию совместных проектов.

Альтернативной современным кластерам моделью организации экономики являются холдинговые структуры, возникшие исторически раньше и сохраняющиеся в централизованных производственных комплексах. Холдинги остаются распространенными во многих отраслях и секторах российской экономики. Однако в современных условиях они имеют существенные ограничения при решении задач оптимального использования ресурсов, развития инноваций [Матюкин 2018: 27].

Исследование моделей формирования и функционирования кластеров актуальное направление в экономической науке. Начиная с основателя концепции кластеров М. Портера, в зарубежной науке вопросы формирования кластеров, их роли в обеспечении конкурентоспособности территории исследовали К. Кетелс, О. Солвелл, М. Кастельс, М. Энрайт, И. Толенадо, Д. Солье, Е. Дахмен, В. Фельдман, М. Трайс, В. Памингер.

Формированию и особенностям функционирования территориально-производственных комплексов как интеграционных структур в советской экономике посвящены работы Н.Н. Баранского, Н.Н. Колосовского, А.Г. Гранберга, А.Н. Пилясова, А.О. Полынева.

Развитию современных кластерных моделей посвящены труды российских ученых Л.С. Маркова, Г.Б. Клейнера, А.П. Градова, В.И. Суслова, С.В. Убеля. Крайне актуальны научные исследования кластеров, реализуемые учеными НИУ Высшая школа экономики (Л.М. Гохберг, М.Ю. Голанд, Е.С. Куценко, 
А.Е. Шадрин и др.) в кооперации с управленцами-практиками (И.М. Бортник, А.Н. Клепач и др.).

Сложными в науке и практике управления кластерными системами являются проблемы сценарных условий и моделей формирования кластеров. Механизмы формирования территориально-производственных кластеров таким путем, как трансформация их из существующих холдинговых структур, - востребованная исследовательская задача в отечественной экономической науке и практике.

В статье исследованы сценарные модели формирования территориальнопроизводственных кластеров путем их трансформации из существующих холдинговых структур для решения задач перехода экономических систем на инновационные модели организации и развития, формирования новых источников роста высокотехнологичной экономики.

Анализ кластерных инициатив, реализованных в разных странах, показывает, что их высокая конкурентоспособность основана на преимуществах модели «цепочки создания добавочной стоимости», которая оптимизирует издержки ее участников, формирует комфортную среду генерации и реализации инноваций.

По результатам обобщения исследований зарубежных и отечественных кейсов кластеризации [Матюкин, Фокин 2019; Абашкин и др. 2015; Иванова, Тарасенко, Хафизов 2015; Тарасенко 2014] автор определяет 4 сценарные модели трансформации холдинговых структур в кластеры, а также объекты производимых изменений (см. табл. 1).

Таблица 1

\section{Модели трансформации холдингов в кластеры}

\begin{tabular}{|c|c|c|}
\hline № & Название модели & Объекты изменений \\
\hline 1 & $\begin{array}{l}\text { Аутсорсинг при сохранении } \\
\text { ключевых компетенций за якорным } \\
\text { участником }\end{array}$ & $\begin{array}{l}\text { Цепочка формирования добавочной } \\
\text { стоимости }\end{array}$ \\
\hline 2 & $\begin{array}{l}\text { Трансформация производственной } \\
\text { инфраструктуры при сохранении } \\
\text { ключевых компетенций за якорным } \\
\text { участником }\end{array}$ & $\begin{array}{l}\text { Цепочка формирования добавочной } \\
\text { стоимости } \\
\text { Производственно-технологическая } \\
\text { инфраструктура }\end{array}$ \\
\hline 3 & Развитие по модели спин-офф & $\begin{array}{l}\text { Цепочка формирования добавочной } \\
\text { стоимости } \\
\text { Организация НИОКР } \\
\text { Производственно-технологическая } \\
\text { инфраструктура }\end{array}$ \\
\hline 4 & $\begin{array}{l}\text { Реализация совместных проектов, } \\
\text { в т.ч. на основе кросс-кластерного } \\
\text { подхода }\end{array}$ & $\begin{array}{l}\text { Цепочка формирования добавочной } \\
\text { стоимости } \\
\text { Организация НИОКР } \\
\text { Производственно-технологическая } \\
\text { инфраструктура } \\
\text { Сетевые каналы взаимодействия между } \\
\text { организациями-участниками }\end{array}$ \\
\hline
\end{tabular}

Рассмотрим реализацию моделей с учетом практических кейсов.

Первый сценарий актуален для крупных производственных холдингов с большим числом переделов в хозяйственной цепочке. По сути, в нем реализация сценария кластеризации состоит в реструктуризации производственных процессов с точки зрения выделения: 
1) ключевых стадий, реализующих уникальные компетенции, формирующие конкурентоспособность продукции кластера;

2) прочих производственных и сервисных стадий, возможных и экономически целесообразных для выполнения сторонними поставщиками, работающими в конкурентной среде.

Экономические предпосылки реализации модели состоят в том, что каждая производственная стадия в кластере исполняется компаниями, имеющими целевые специализации именно на продуктах или сервисах своего производственного передела. При этом они могут работать не только на предприятия кластера, но и на компании за пределами территории, максимально используя свою технологическую базу и реализуя экономические преимущества эффекта масштаба.

Якорное предприятие кластера оставляет за собой производственные стадии с ключевыми компетенциями, являющимися залогом конкурентоспособности конечного продукта и, как правило, обладающими наибольшей добавочной стоимостью. Обычно это НИОКР, инжиниринг, выпуск конечного продукта, управление брендом продукта и системами его продаж. Поставщиками на промежуточных стадиях поставляются материалы, изготавливаются комплектующие и компоненты, предоставляется сервисное обслуживание и оказываются прочие вспомогательные услуги.
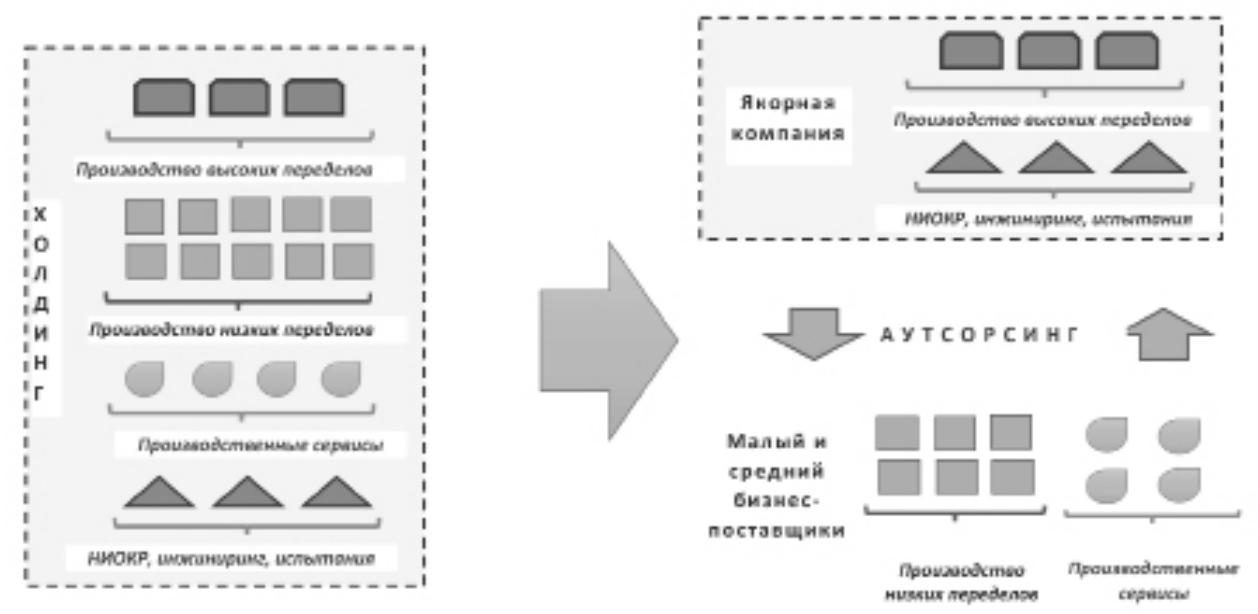

Рисунок 1. Сценарий трансформации по модели активного аутсорсинга

Практическая реализация данной модели возможна при текущем наличии или потенциальной возможности создания компаний - «гарантированных поставщиков» на территории перспективного кластера, реализующих второстепенные производственные и сервисные стадии.

Практически по данной модели кластеров функционируют крупнейшие мировые авиа- и автомобилестроительные компании, в числе которых авиастроительные гиганты Boeing и Airbus, автозавод Fiat и др. Так, авиастроительный кластер корпорации Boeing объединяет в единую производственную цепочку деятельность более 200 дочерних компаний, которые координируют деятельность около 5 тыс. поставщиков. В данном случае кластерные взаимодействия реализуются в транснациональной производственной системе [Тарасенко 2014: 923].

В российской практике трансформация холдинга в кластер по данной модели 
осуществляется в рамках модернизации работы государственных компаний Объединенной авиастроительной корпорации (далее - ОАК) и Объединенной двигателестроительной корпорации. Так, существовавшая производственная модель ОАК была сформирована в 30-40-х гг. XX в. и опиралась на авиационные заводы полного цикла, распределенные по всей территории страны. Уровень кооперации был низким, и каждый авиационный завод являлся производственным предприятием полного цикла. В рамках реализуемого с 2006 г. реформирования производственной деятельности, предусматривающего создание авиационных кластеров, предприятия ОАК сохранили за собой только ключевые компетенции: инжиниринг, сборку готового изделия и управление корпоративным брендом. Ключевое внимание уделяется процессу перераспределения заказов между квалицированными поставщиками корпорации, что предполагает перевод на них производственных этапов низкого уровня. Такая модель реорганизации холдинга позволила устранить серьезные издержки, существующие диспропорции по производственным площадям и мощностям, число устаревшего оборудования, когда более 80-90\% деталей и сборочных единиц производилось в цехах одного предприятия-монополиста.

Данная модель имеет наибольшие перспективы в реформировании сложных распределенных производственных систем с большим числом хозяйственных переделов и объединенных технологическими платформами высокого уровня.

Вторая модель трансформации основывается на тех же предпосылках и моделях производственных связей, что и первый подход, однако из-за существенных особенностей считаем необходимым выделить ее в отдельный сценарий. Она предполагает, что реформируемый холдинг при отказе от низкомаржинальных этапов обладает обширной производственной инфраструктурой, которая может быть использована для создания промышленных парков и технопарков с целью передачи этапов «нижних» переделов на квалифицированных поставщиков - их резидентов. При этом предусматривается ускоренное «выращивание» производственных партнеров - компаний малого и среднего бизнеса путем предложения им готовой производственной базы, ранее используемой холдингом. Ключевые компетенции и производственные этапы с высокой добавленной стоимостью, как и в первой модели, остаются за якорным предприятием кластера.

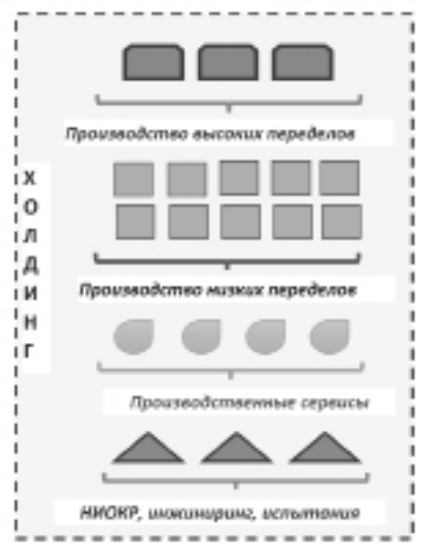

А. Ходжиттопая структура

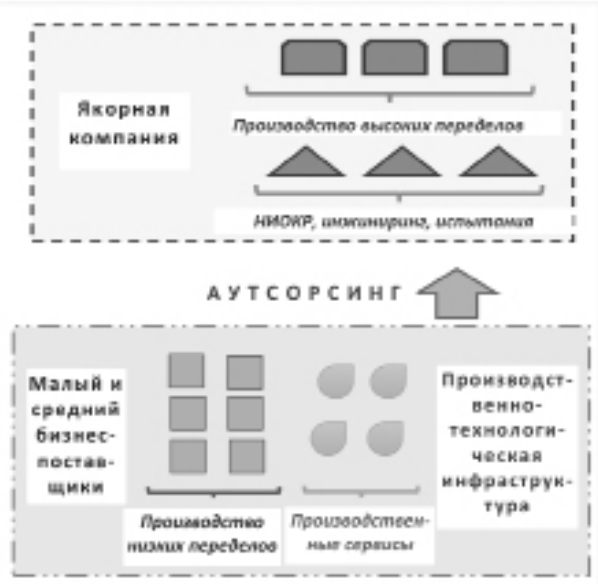

b. Kластер

Рисунок 2. Сценарий трансформации производственной инфраструктуры 
В рамках данного сценария должны выполняться следующие условия:

1) реформируемый холдинг должен иметь собственную развитую промышленную инфраструктуру, при необходимости - возможность вложиться в ее модернизацию для доводки до современного стандарта промпарка или технопарка;

2) имеется потенциал создания критической массы предприятий малого и среднего бизнеса, готовых организовать производственную деятельность на предоставляемых в приобретение или аренду мощностях.

В данной модели должна быть проведена организационная настройка нового производственного комплекса через создание управляющей компании для промышленной инфраструктуры. Ее задачами являются управление функционированием производственной площадки, привлечение резидентов - производственных партнеров в кластер, создание условий для повышения его инвестиционной привлекательности. Последнее подразумевает возможность использования особых режимов для производственных зон, вхождение в программы государственной поддержки.

Примерами такой трансформации является практика формирования кластеров - «полюсов конкурентоспособности» во Франции, где в ряде случаев такие территориально-производственные зоны стали создаваться на переформатированных площадках крупных промышленных гигантов.

Примером российской практики является Камский индустриальный парк «Мастер», организованный в 2011 г. на базе площадей дочернего завода ПАО «КАМАЗ». Он представляет собой совокупность производственных и офисных площадей с полностью подготовленной инфраструктурой, ориентированной на машиностроительную отрасль. Его появление было вызвано необходимостью в короткие сроки создать современные, экономически эффективные производства по выпуску автокомпонентов для якорного предприятия ПАО «КАМАЗ». В свою очередь, якорное предприятие в роли производственного «финишера» предоставляет гарантированные заказы для резидентов на их продукцию при условии соблюдения параметров «цена - качество».

«Выращивание поставщиков» происходит через предоставление компаниям-резидентам конструкторско-технологической документации на требуемую финишером продукцию, обучение производственных партнеров, а также помощь в разработке, внедрении и сертификации систем менеджмента качества, бережливого производства для синхронизации с производственными стандартами ПАО «КАМАЗ» 1 .

Третий сценарий предусматривает создание кластера по модели спин-офф. Он предполагает качественное организационное изменение производственной системы на основе инвестирования в инновации и подхода управления жизненными циклами новых проектов. Поддерживаемые якорным предприятием научно-технические разработки перерастают в новые проектные направления, а затем - в самостоятельные малые инновационные компании, функционирующие в ближайшем внешнем окружении холдинга и формирующие внешний инновационный кластер.

Выгоды для головной организации холдинга, которая становится якорной компанией кластера, состоят в создании новых быстро разворачиваемых востребованных рынком продуктов или производственных направлений при сохранении своих ключевых компетенций, а также в привлечении новых инвестиций без страха потери основного бизнеса. В свою очередь, возникающие

1 Камский индустриальный парк «Мастер». Доступ: https://russiaindustrialpark.ru/sites/ default/files/industrialnyy_park_kip_master_prezentaciya.pdf (проверено 28.08.2020) 


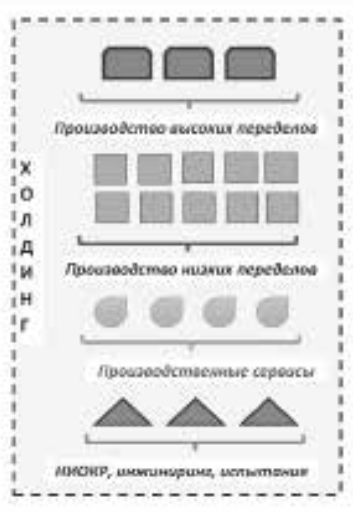

A. Холаинговая структура

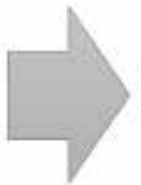

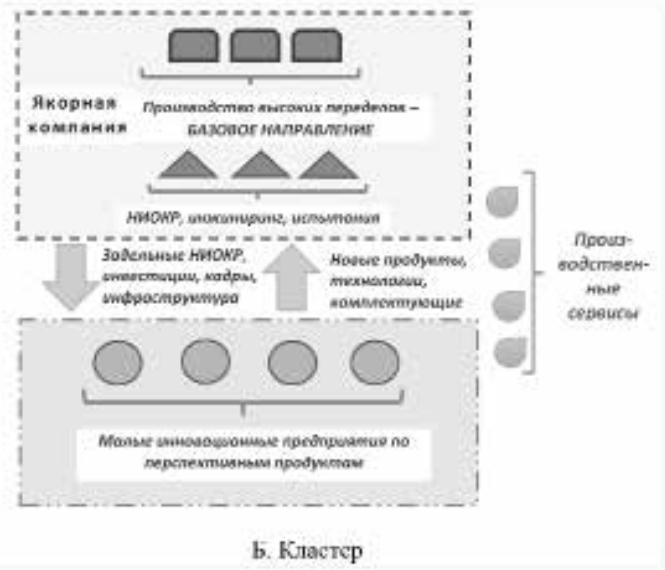

Рисунок 3. Сценарий трансформации по модели спин-офф

малые инновационные компании пользуются опытом, ресурсами, каналами дистрибуции и зачастую клиентами материнской компании, значительно уменьшая собственные риски.

Предпосылками реализации данной модели являются:

1) рыночные запросы на новую продукцию по профилю деятельности холдинга;

2) значительный инновационный потенциал холдинга, выражающийся в заделах новых НИОКР, перспективных для коммерциализации;

3) кадровый потенциал для запуска инновационных направлений в «проектном режиме», источники его пополнения.

Примером развития кластера такого типа являются практики компаний Силиконовой долины в США - многие предприятия сферы микроэлектроники, приборостроения и информационных технологий изначально появились как «дочки» крупных якорных компаний - Cisco, IBM, Microsoft. Первоначально они выделились из структуры холдинговых материнских компаний для работы над перспективными проектами.

Модернизация российских холдингов по данному сценарию происходит в практике ряда инновационных кластеров. Так, промышленный кластер «Биомед» Пензенской обл. вплоть до 2012 г. развивался как холдинг на базе якорного предприятия «МедИнж», сосредоточившего на своей производственной базе полный цикл разработки и изготовления медицинских изделий для кардиохирургии. С развитием новых производственных направлений и проектов на перспективных рыночных нишах была выбрана модель кластера. Стартапы - новые компании -создавались при успешном завершении НИОКР, становились юридически и финансово независимыми от якорной компании. В дальнейшем в качестве отдельных компаний из холдинга вышли направления производства материалов, комплектующих, предоставления сервисных услуг - они стали самостоятельными бизнес-единицами из-за повышения спроса на их продукцию со стороны растущего числа компаний нового кластера.

Такая модель формирования кластера лежала и в основе создания научнопроизводственного кластера «Сибирский наукополис», подмосковного инновационного кластера «Фарм Долина».

Четвертый сценарий создания кластера связан с модернизацией организационной и производственной системы холдинга, которая происходит в рамках его участия в совместных партнерских проектах. Такие проекты требуют 
создания новых компаний совместно с внешними по отношению к холдингу структурами, обладающими необходимыми для их реализации компетенциями, которые в холдинге отсутствуют. Особенность формирования такой кластерной модели состоит в том, что подобные проекты часто основываются на кросс-секторальном подходе: традиционные технологии в отраслях работы холдингов дополняются новыми технологическими направлениями компаний-партнеров. По результатам таких проектов могут возникать новые области и целые индустрии.

Подтверждение перспективности данной модели кластеров обосновано в исследованиях современных экономистов Б. Асхайма и М. Гертлера, выявивших, что чем более наукоемкой является экономическая деятельность, тем более свойственно ей стремление быть кластеризованной [Asheim, Gertler 2005: 295].

В данной модели взаимодействия компаний-участников кросс-кластерных проектов могут носить удаленный характер, происходить в сетевом формате, а кластеры могут быть межстрановыми или транснациональными. По сути, доминантой данного типа кластерного образования является инновационный проект, базирующийся на новой технологии или технологической платформе, под который формируются цепочки научных, технологических и производственно-хозяйственных связей между его участниками.

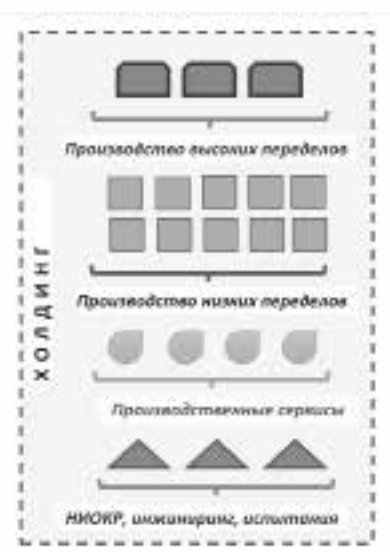

А. Ховаиненая струкіура

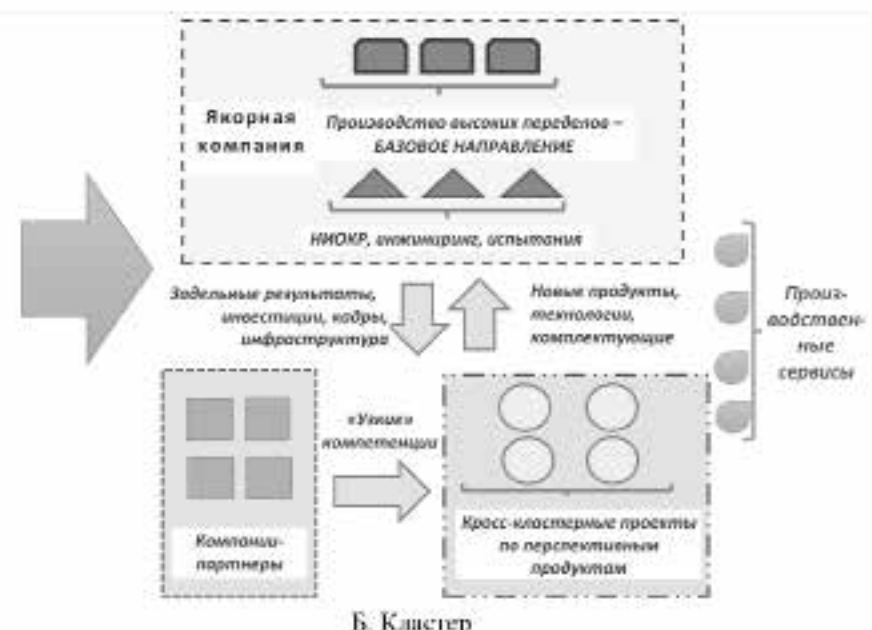

Б. Кластер

Рисунок 4. Сценарий трансформации по модели кросс-кластерных проектов

Условиями создания и реализации данной модели кластеров являются:

1) значительный инновационный потенциал холдинга для проведения НИОКР по «задельным» областям, доступность научной и технологической базы для их реализации;

2) выявление холдинговой компанией отсутствующих компетенций для перспективных проектов и поиск партнеров, обладающих ими;

3) ресурсные возможности для формирования и сохранения технологического лидерства при выходе на рынки с новым продуктом.

Примером таких кластеров является сформированный в 2010-е гг. кластер персонализированной медицины Фламандского региона (Бельгия). Проект Nano for Health воплощался на базе группы холдинговых предприятий медицины и нанотехнологий и привел к трансформации медицинских предпри- 
ятий в высокотехнологичную инновационную область персонализированного здравоохранения [Fici et al. 2016: 13].

Отечественные практики развития холдингов на основе кросс-кластерных проектов очень ограниченны. Примером является кейс кооперации автохолдинга ПАО «КАМАЗ» с компаниями - разработчиками программного обеспечения Cognitive Technologies и «ВИСТ Групп» в рамках проекта создания беспилотного грузового автомобиля. Проект потребовал совместной работы автопредприятия, ИТ-компаний, предприятий приборостроения - производителей аппаратного обеспечения. Он стал основой развития отечественного кластера беспилотного грузового транспорта в рамках направления «Автонет» Национальной технологической инициативы [Куценко, Исланкина, Киндрась 2018: 33].

Таким образом, можно отметить, что модернизация производственной деятельности холдингов в эффективные структуры кластерной кооперации может быть реализована в моделях с различной методологией трансформации в зависимости от начальных условий текущего состояния холдинга, целей создания кластера, типа целевого рынка и продукта, проектных особенностей взаимодействия участников. Современные кластеры делают более эффективными цепочки производственных систем, формируют принципиально новые продукты и индустрии за счет сложных кооперационных взаимодействий участников.

В то же время зарубежный опыт создания кластеров - технологических лидеров, а также отдельные российские кейсы кластеризации демонстрируют важность выбора правильного способа трансформации холдинга, опоры на методические рекомендации и учета передовой практики ранее реализованных проектов.

Статья подготовлена в рамках поддержанного гранта РФФИ, проект N 18-310-00253\19.

\section{Список литературы}

Абашкин В.Л., Артемов С.В., Гершман М.А., Гохберг Л.М., Киндрась А.А., Куценко Е.С., Рудник П.Б., Шадрин А.Е. 2015. Пилотные инновационные территориальные кластеры в Российской Федерации: направления реализации программ развития. М.: НИУ ВШЭ. 326 с.

Иванова В.Н., Тарасенко В.В., Хафизов Р.Р. 2015. Европейский опыт реализации кластерной политики. - Известия Волгоградского государственного технического университета. № 3(158). С. 43-49.

Куценко Е., Исланкина Е., Киндрась А. 2018. Можно ли быть умным в одиночестве? Исследование инновационных стратегий российских регионов в контексте умной специализации. - Форсайт. Т. 12. № 1. С. 25-45.

Матюкин С.В. 2018. Классификация преимуществ кластера как модели эффективной организации производственного комплекса. - Инновации и бизнес - Поволжье. № 2(4). С. 27-32.

Матюкин С.В., Фокин А.Е. 2019. Анализ развития кластеров высокотехнологичных секторов: адаптация зарубежного опыта для модернизации экономики региона. - Фундаментальные исследования. № 1. С. 33-39.

Тарасенко В.В. 2014. Американская, европейская и азиатская модели реализации кластерной политики. - Экономика и предпринимательство. № 9(50). C. 921-924.

Asheim B., Gertler M. 2002. The Geography of Innovation. - The Oxford Handbook of Innovation (ed. by J. Fagerberg, D.C. Mowery, R.R. Nelson). P. 291-317.

Fici L., Malyzhenkov P.V., Piccarozzi M., Meleshina E.S. 2016. Spin-off Design as an Organizational Practice: A Methodological Approach. - Business Informatics. Vol. 3. No. 37. P. 7-14. 
MATYUKIN Sergey Vladimirovich, Cand.Sci. (Econ.), Associate Professor of the Chair of Management and Economic Security, Penza State University (40 Krasnaya St, Penza, Russia, 440026; msv@mbpenza.ru)

\title{
MODELS OF TRANSFORMATION OF THE HOLDING COMPANIES STRUCTURES INTO CLUSTERS: SCENARIOS UNDER THE CONTEXT OF THE RUSSIAN ECONOMY
}

\begin{abstract}
Modern economists have proved that production holding companies widespread in numerous economic fields have essential limits in solving problems of appropriate resources using and innovations development .Clusters are effective models of production complexes organization. The author made a research of scenery models of territorially production clusters formation by means of their transformation from existing holding companies. It contributed to solution of problems of economic system transition into innovation models of organizing and development, formation of new highly efficient growth sources of high-technology economy.
\end{abstract}

Keywords: cluster policy, territorial clusters, holding companies transformation, cluster formation model, potential capacity of clustering

\section{УДК 321 (478)}

ОСИПОВА Светлана Анатольевна - доктор политических наук, профессор кафедры политологии и государственного управления Приднестровского государственного университета им. Т.Г. Шевченко, Приднестровская Молдавская Республика (3300, Молдова, Тирасполь, ул. 25 Октября, 107; vrednotta@yandex.ru)

КОРОТКОВА Ольга Александровна - преподаватель кафедры социологии и социальных технологий Приднестровского государственного университета им. Т.Г. Шевченко, Приднестровская Молдавская Республика (3300, Молдова, Тирасполь, ул. 25 Октября, 107; korolgaо@таil.ru)

\section{ГЕНЕЗИС И СТАНОВЛЕНИЕ ПРИДНЕСТРОВСКОЙ ГОСУДАРСТВЕННОСТИ}

Аннотация. В статье представлена характеристика основных этапов становления и развития Приднестровской Молдавской Республики, особенностей организационных, политико-правовых и институциональных основ ее государственной системы как самоопределившегося (непризнанного) государства. Кроме того, авторы дают оценку роли гражданского общества в процессе создания независимого Приднестровского государства.

Ключевые слова: самоопределившееся (непризнанное) государство, гражданское общество, съезд народных депутатов всех уровней, Объединенный совет трудовых коллективов

$\Pi$ олитической новацией современного этапа общественного развития является становление государств, граждане которых реализовали право на независимость, но которые так и не были признаны международным сообществом. Одной из важнейших линий актуальной социологической и социально-политической мысли служит дискуссия, касающаяся вопросов непризнанности государственных образований и их влияния на эволюционирование глобальной политики. Наряду с этим стоит отметить, что теоретико-методологические подходы к пониманию и оценке подобного явления весьма многообразны, а порой и противоположны. 